\title{
Performance evaluation of sorption compressor based J-T refrigerator using R134a and mixture refrigerants as working fluids
}

\author{
R N MEHTA ${ }^{1,2}$, S L BAPAT $^{1}$ and M D ATREY ${ }^{1, *}$ \\ ${ }^{1}$ Mechanical Engineering Department, Indian Institute of Technology Bombay, Powai, Mumbai 400 076, India \\ ${ }^{2}$ Mechanical Engineering Department, Dr. S \& S.S. Ghandhy Government Engineering College, Surat 395001 , \\ India \\ e-mail: rnm7228@yahoo.com; slbapat@iitb.ac.in; matrey@iitb.ac.in
}

MS received 30 November 2018; revised 8 May 2019; accepted 22 May 2019

\begin{abstract}
The idea of adsorption based refrigerator was conceived in the year 1961 by Vickers. The present work reports development of a sorption compressor based J-T refrigerator with R134a alone as a working fluid and a three component mixture of R134a, Ethane and Methane. Commercially available activated carbon, obtained from coconut shell, is used as an adsorbent. The reported compressor is a four cell structure and uses isenthalpic expansion of R134a for cooling purpose. A lowest temperature of $-8^{\circ} \mathrm{C}$ is obtained giving $5 \mathrm{~W}$ of refrigeration effect for R134a. The work is further extended to study the effect of various parameters like adsorption-desorption cycle time, heater power input and capillary tube length on the low temperature obtained from the refrigerator. Experiments are then carried out using a three component mixed refrigerant, a low temperature of $-54^{\circ} \mathrm{C}$ at no load is achieved. Also a continuous trouble-free operation is observed.
\end{abstract}

Keywords. Sorption compressor; adsorption capacity; R134a; mixture refrigerants.

\section{Introduction}

The idea of adsorption based cooling was conceived in the year 1961 by Vickers [1]. Adsorption is defined as the process that uses surface forces on solid bodies, called adsorbents, to achieve the concentration of volatile materials defined as equilibrium adsorption capacity [2]. As adsorption takes place on the surface of a solid substance, adsorbents must have large surface area to volume ratio; and the cavities implied by this condition must be reasonably accessible. The surface area within the closed voids is not useful for the adsorption process. When the adsorbate sticks to the surface with van der Waal's force of attraction; such adsorption process is termed as physical adsorption. However, in certain adsorption process, there is also a chemical reaction between the adsorbent and adsorbate, such an adsorption is termed as chemisorption [3]. The absence of any moving component leads to minimum wear and tear and hence a long maintenance free life is the primary advantage of such a refrigerator $[4,5]$. The advantage of this cooler is that the size of the compressor can be easily scaled up and down without any degradation in the performance of the refrigerator. The focus of the current work is not to improve the coefficient of performance or efficiency of the system but to demonstrate usage of single and mixed refrigerant using adsorption compressor.

*For correspondence

Published online: 08 July 2019
The sorption compressor presently developed uses activated carbon as the adsorbent and R134a alone and its mixture with Ethane and Methane as the adsorbate. The adsorption in the current study follows physical adsorption/ desorption process. Activated carbon has been the choice of adsorbent for a wide range of adsorbates, especially for non-polar adsorbates in sub-critical state. As capillary condensation of adsobate takes place in the pores of the adsorbent. This results in an enormous increase in density of the adsorbed fluid and hence the adsorption capacity also increases to a larger value. In the case of polar adsorbates Hydrogen bonding occurs, which generates more heat during exothermic adsorption process. As a result, more heat needs to be supplied to regenerate the adsorbent. However, in the case of non-polar adsorbent, the bond strength is lower and hence the heat required for regeneration is also of lower level. Therefore, non-polar working fluids (adsorbate) are considered in the present case. Hence, crystalline adsorbents like activated alumina or molecular sieves used for polar adsorbates like water, ammonia are not considered. This is one of the most important reasons for choosing activated carbon with non-polar adsorbates. Considering these criteria, for the current work activated carbon is used as the adsorbent. It is produced from coconut shell. Steam is used for activation of pores, a kiln temperature of $850-900^{\circ} \mathrm{C}$ is maintained for a process time of $9 \mathrm{~h}$. The mesh size is $30 \times 50$. The commercial name given by the manufacture M/S Active carbon India Pvt. Ltd, India 
to the carbon is ACG-90. The carbon is selected due to its higher micro pore content.

The details of activated carbon used are as given:

\section{Base}

Activation Agent

CTC

Iodine Value (Min.) mg/gm

Moisture (Max.)

Ash (Max.)

$\mathrm{pH}$

Surface area $\mathrm{m}^{2} / \mathrm{gm}$

Mesh Size
Coconut Shell Charcoal

Steam-Air

$90 \%$

1450

$5 \%$

$3 \%$

Alkaline

1550

$30 \times 50$
The adsorption capacity of any adsorbent, increases with the increase in pressure and/or decrease in temperature and vice-versa. Therefore, desorption of the adsorbed gas can be carried out either by (1) increasing temperature, Temperature Swing Adsorption (TSA), (2) lowering pressure, Pressure Swing Adsorption (PSA) and (3) combination of both. The quantity of gas left in the adsorbed state after completion of desorption/discharge process is referred here as the residual loading or heal. This residual loading decides the method of desorption, either Pressure Swing Adsorption (PSA) or Temperature Swing Adsorption (TSA). PSA generally allows for high residual loading as compared to TSA [3]. The phases of desorption and adsorption could be used as pressurization and depressurization in a given volume, in a device termed as sorption compressor $[6,7]$. In the present work, sorption compressor using TSA method is used to drive the cooler using R134a lone and its mixture with Ethane and Methaneas as the working fluids. The requirement of vibration free and reliable operation has led to the development of sorption compressor based J-T cooler. Also the use of low grade heat energy has motivated the development of such a cooler.

The current work presents the effect of operating parameters like heater power input, cycle time and refrigeration load on low temperature achieved. Also the effect of capillary tube diameter $0.78 \mathrm{~mm}\left(0.031^{\prime \prime}\right)$ of length $3 \mathrm{~m}$ and $4 \mathrm{~m}$ on low temperature achieved for two different cycle times is determined experimentally. The work presented by Prasad et al [8] has characterized adsorbent for its adsorbent capacity using Nitrogen to determine the adsorption chamber size. Their model does not take into account the effect of voids inside the adsorber chamber and hence pressure variation with time. In order to make the compressor suitable for a variety of refrigerants, in the current work, apart from considering the adsorption capacity of the adsorbent, the sizing of the adsorption chamber is also carried out based on the characterization of the sorption compressor discharge with time using
Nitrogen. Considering poor adsorption capacity of Nitrogen, the compressor is expected to have a constant discharge at nearly constant pressure for most of the working fluids with adsorption capacity equal to or higher than that of Nitrogen. The compressor is also characterized for variation of discharge pressure with time using various working fluids [9]. In the case of R134a, a sub-critical fluid, the adsorption capacity is appreciably higher compared to super-critical fluids like Nitrogen; the variation of discharge pressure with time is not expected to be significant. The characterization of the adsorbent was presented earlier in [9] and the result of preliminary continuous operation of the cooler was presented in [10]. The present paper describes the long term usage of such a refrigerator based on sorption compressor to achieve temperatures below $-8{ }^{\circ} \mathrm{C}$.

\section{Schematic of the sorption compressor and its working}

The layout of the present Sorption compressor is shown in figure 1. $\mathrm{C} 1$ to $\mathrm{C} 4$ are the adsorption/desorption chambers. The chambers are heated with Nichrome tubular electrical heaters placed inside the chambers or cooled using water as the coolant on the outer side of the cylindrical surfaces. The adsorption chambers (through the after-cooler and a set of valves) are connected to the return gas heat exchanger, J-T device, and evaporator.

The working gas is initially adsorbed in the adsorber chambers $\mathrm{C} 1$ to $\mathrm{C} 4$. The chambers $\mathrm{C} 1$ and $\mathrm{C} 3$ form one pair of chambers. Similarly, C2 and C4 form the other pair of chambers and these two pairs are operated cyclically as explained below. The heating process is assumed to start from the chamber $\mathrm{C} 1$. The heating causes an increase in the temperature of the adsorbent (activated carbon) and thus reduces the adsorption capacity. This leads to the desorption process and the adsorbed gases are liberated in the void volume arising out of inter particle space and meso-pores of

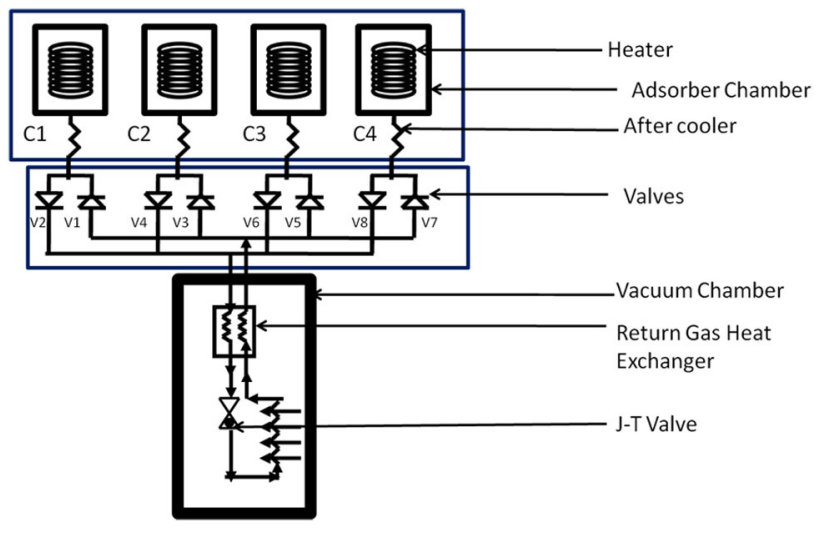

Figure 1. Layout of a sorption compressor based J-T refrigerator. 
adsorbent leading to increase in the gas pressure [11]. On reaching appropriate discharge pressure, the discharge valve is opened and high pressure gas flows out of the adsorption chamber. The discharge pressure at this stage is a function of the rate at which gas is released from the adsorbent and the mass flow rate flowing out of the bed $[7,8]$. The gas then passes through the after-cooler where it is cooled by chilled water $\left(16^{\circ} \mathrm{C}\right)$. The cooled high pressure gas passes further through the return gas heat exchanger before passing through the capillary tube acting as the throttling device, thus producing low temperature in the evaporator of the system. The gas takes up the heat load at the evaporator and traverses back to the chamber $\mathrm{C} 3$ through the return gas heat exchanger cooling the incoming gas. The heating process follows the adsorption process. Therefore, the adsorber chamber at the beginning of the heating process is at ambient temperature. The adsorption/ desorption being an intermittent process; more than two cells are required to have a continuous flow available at high pressure $[6,9]$. Hence two pairs of chambers are provided, $\mathrm{C} 1-\mathrm{C} 3$ and $\mathrm{C} 2-\mathrm{C} 4$. The valves $\mathrm{V} 2, \mathrm{~V} 4, \mathrm{~V} 6$ and $\mathrm{V} 8$ act as discharge valves for the corresponding cells $\mathrm{C} 1$, $\mathrm{C} 2, \mathrm{C} 3$ and $\mathrm{C} 4$ and the valves V1, V3, V5 and V7 act as suction valve for the corresponding cell. The adsorption process, in effect, is similar to suction process in the conventional reciprocating compressors resulting in a closed loop circulation of the working fluid [10]. In principle, subsequent cells are heated to ensure continuous flow.

In the present case a four cell unit is adopted to carry out heating, discharge, cooling and adsorption process on a continuous mode. The after cooler and return gas heat exchanger are designed and fabricated for the current work. The thermal conductivity of the activated charcoal is poor, and is of the order of $0.15 \mathrm{~W} / \mathrm{m} \mathrm{K}$ only $[11,12]$. This results in a temperature gradient inside the adsorption chamber [13]. A thermal analysis is carried out for pipe diameter of 50, 80 and $100 \mathrm{~mm}$ of the adsorber chamber for the temperature gradient in the radial direction. The theoretical analysis suggests that least temperature gradient exists, on steady state, for a $80 \mathrm{~mm}$ diameter chamber with heating elements placed on a $50 \mathrm{~mm}$ pitch circle diameter (PCD) to form a hexagon [10]. Hence, $80 \mathrm{~mm}$ diameter adsorber chamber with hexagonally placed heating elements at $50 \mathrm{~mm}$ PCD is selected for the present work.

\section{Theoretical equilibrium adsorption capacity}

The selection of an adsorbent in any process is based on adsorbent properties like equilibrium adsorption capacity, selective adsorbtivity, regenerability, kinetics of adsorption process, compatibility and finally the cost. The adsorbate/working fluid is selected based on the thermophysical properties like low temperature requirement, latent heat of vaporization, safety and environmental hazards. In the present case for initial experiments R134a is selected as the working fluid on account of its high critical temperature $\left(101.08^{\circ} \mathrm{C}\right)$. On account of this, the capillary condensation in the adsorbent pore leads to a higher adsorption capacity in the range of $50-60 \%$ of adsorbent mass $[10,11]$. This is considerably higher compared to super critical gases like Nitrogen, wherein the adsorption capacity is in the range of $3-3.5 \%$ of adsorbent mass $[6,14]$. The condensing temperature and pressure are $30^{\circ} \mathrm{C}$ and $7.7 \mathrm{bar}$, which can be easily attained in the sorption compressor. The higher latent heat of vaporization is another advantage of R134a. The adsorption of R134a, which can be considered in the category of hydrocarbons, non-polar activated carbons have been the choice for the present work. Once the operation of the cooler is realized and a complete diagnostics are developed, a mixture of R134a, Ethane and Methane is used as the working fluid to attain a further low temperature. It is to be noted that, higher the micro pore volume, the better it is from adsorption point of view. However, the major problems of these amorphous carbons are inconsistent properties leading to variation in equilibrium capacity. Keeping this in mind characterization for these adsorbents is a pre-requisite. The mechanism for adsorption in micropores is that of pore-filling rather than layer-by-layer surface coverage, generally applies well to adsorption pairs involving only van der Waals forces and is especially useful to describe adsorption on activated carbon [14].

The equilibrium capacity of a gas on micro porous activated carbon is calculated from the DubininRadushkevich (DR) equation [13], as shown below in Eqs. (1) and (2).

$$
\begin{gathered}
W=W_{0} \rho \exp \left(-\left(\frac{A}{\beta_{a} E_{0}}\right)^{2}\right) \\
A=R T \ln \left(\frac{p_{s}}{p}\right)
\end{gathered}
$$

where, $W$ is the equilibrium adsorption capacity in grams of adsorbate per gram of adsorbent $(\mathrm{g} / \mathrm{g})$, Wo is the micro-pore volume in the adsorbent $0.082 \mathrm{cc} / \mathrm{gram}$ of adsorbent. Since, the data was not directly provided by the manufacturer, Wo is calculated from adsorption capacity of Ethane using the same values parameter $\beta_{a} E_{o} . \rho$ is the density at adsorption condition. Parameter $A$ is the adsorption potential calculated by using Eq. (2). $\beta_{a}$ is the shifting factor for enabling superimposition of different adsorbates on the same adsorbent. It is also called as affinity coefficient, usually taken 1 for benzene. $E_{o}$ is the characteristic energy of the surface of the adsorbent and a function of micro-porous structure of a given adsorbent. It is also a function of adsorbent and adsorbate combination and is independent of physical condition of adsorption. The value of product $\beta_{a} E_{o}$ for R134a is $13.72 \mathrm{~kJ}$ [15-17]. 


\section{Design of heating system}

In the sorption compressor, electrical heaters are used to supply heat to the adsorbent to desorb the gases. This heat is conducted away by the activated carbon. The thermal conductivity of adsorbent material is low while heat generation is steady. This results in a temperature gradient across the adsorption chamber in radial direction. A uniform temperature distribution is desirable to ensure uniform desorption of gases which leads to better throughput. Otherwise, a larger adsorber chamber would be required for the same throughput. One of the approaches to have a uniform temperature distribution is to maintain the length to diameter ratio of adsorber chamber as high as possible [9]. A computer code using the finite volume methodology is written to determine the theoretical temperature distribution at steady-state condition across the adsorption chamber. It considers the packed adsorbent bed as material with no porosity having identical physical properties as the porous bed. In order to arrive at a better temperature distribution, this code is run with different number of heating elements, located at different pitch circle diameters. The results of computer code for 6-heater arrangement, placed in a hexagonal fashion at $50 \mathrm{~mm}$ pitch circle diameter for a $80 \mathrm{~mm}$ diameter chamber, show an improved temperature profile, as shown in figure 2 [9]. It is also inferred from the temperature distribution that, the pockets of low temperature towards the outer periphery and between two heating elements may not contribute to the compressor throughput. On the other hand, the gases liberated in the core may get adsorbed in these pockets on the periphery on account of their comparatively lower temperature. The temperature distribution inside the adsorber cell using a six heater arrangement at

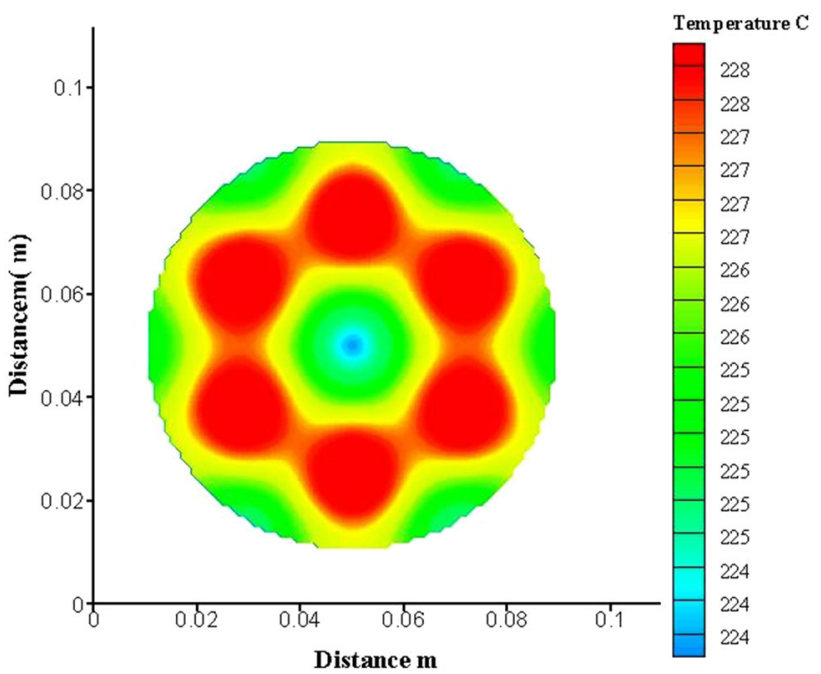

Figure 2. Temperature distribution for $80 \mathrm{~mm}$ diameter chamber with 6-heater arrangement [9].
$50 \mathrm{~mm}$ pitch circle diameter is adopted. This arrangement is found to have better temperature distribution compared to other possible arrangements. The present heating arrangement is used to get the best possible temperature distribution.

\section{Characterization of adsorbent}

The design of sorption compressor for such a refrigerator involves characterization of the adsorbent for equilibrium capacity, design of heating system for effective desorption of the adsorbed gas, design of gas distribution system for effective utilization of the adsorption capacity of the adsorbent. The adsorption capacity of activated carbon depends on its formation process and hence differs from source to source. Two different experimental set-ups are fabricated to develop understanding of the system behavior and to generate data related to equilibrium adsorption capacity.

i. Single cell set-up to determine the adsorption capacity for the adsorbate.

ii. Two cell sorption compressor set-up to study the compressor discharge characteristics.

A single cell unit as shown in figure 3 [9], is fabricated to determine the adsorption capacity of the adsorbent. The discharge characteristics are essentially a function of the amount of adsorbent, the adsorption capacity for the adsorbate, desorption temperature and its uniformity, and system void volume. Also, the effects of gas distribution inside the adsorption chamber and heater power on high pressure generated are important factors for the design of sorption compressor. A two-cell sorption compressor is fabricated to characterize the sorption compressor for variation of discharge pressure with cycle time [9, 10]. The final experimental set-up is arrived at based on the data generated using a single cell unit for the adsorption capacity and a two cell unit for the discharge characteristics.

The two cell sorption compressor set-up similar to a single cell set-up, shown in figure 3 was used to determine the temperature distribution across the cell in the radial direction and to study discharge pressure characteristics. Temperature sensors are provided at three different locations inside the cell (a) on the surface of the heating element, (b) on the inner side of the body at the farthest point from the heater and (c) in between the heater surface and the body inner surface. Experiment is conducted using nitrogen alone as the working substance. During the heating and subsequent desorption process the heater surface reached a maximum temperature of $210^{\circ} \mathrm{C}$. The temperature in the bed is observed to be around $85^{\circ} \mathrm{C}$, the temperature gradient between the heater surface and adsorbent is attributed to the poor thermal conductivity of the 


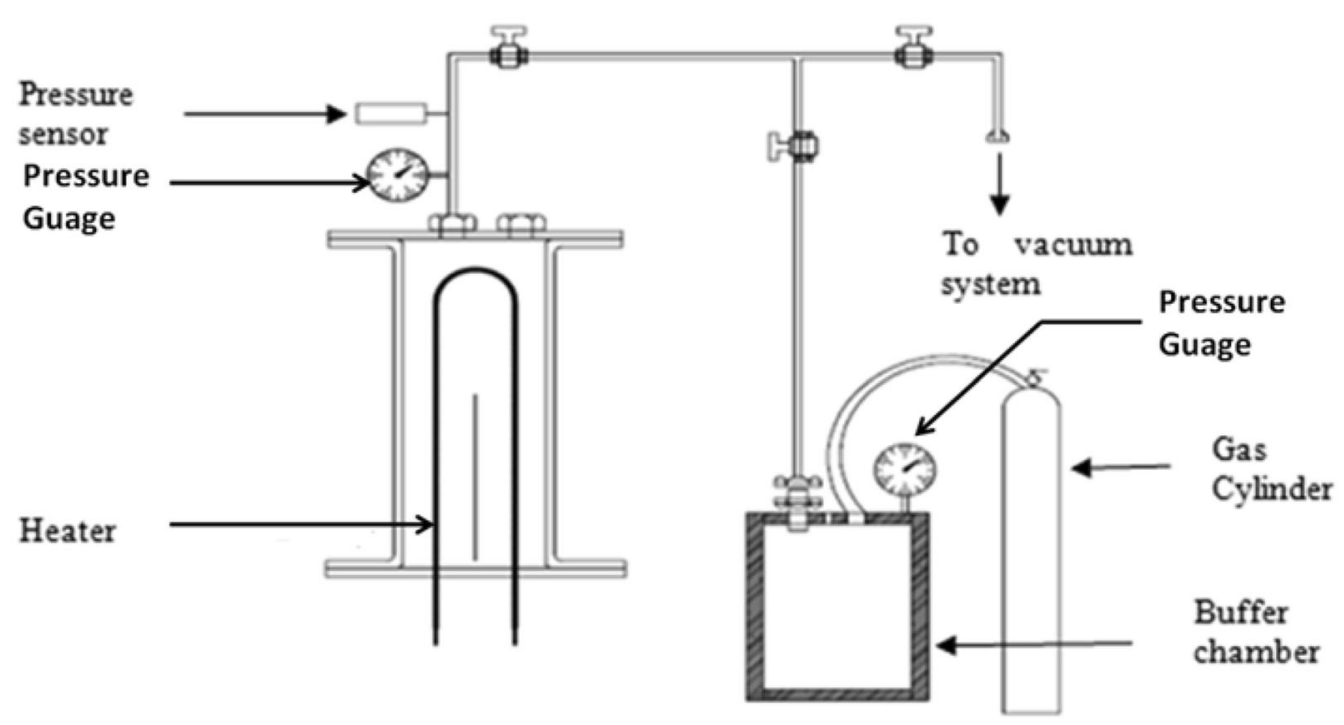

Figure 3. Single cell set-up to determine adsorption capacity [9].

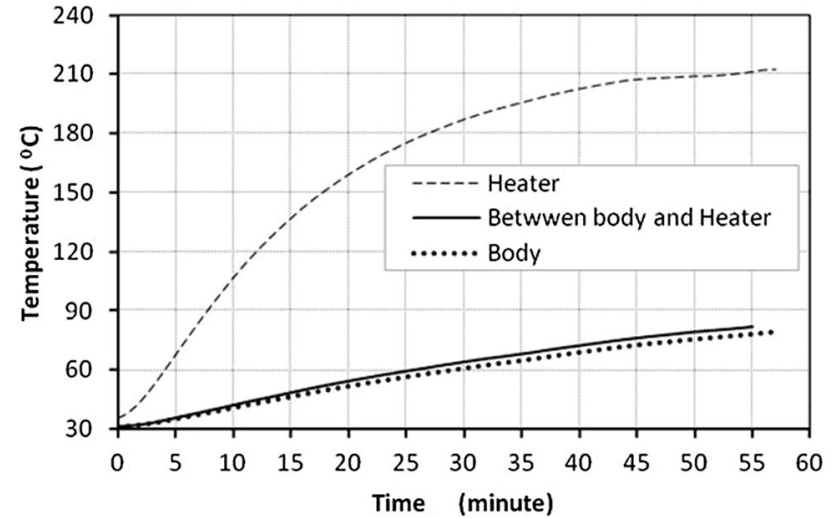

Figure 4. Temperatures inside the adsorber chamber during heating and desorption process [9].

activated carbon. Figure 4 shows the increase in temperature with time when power of $665 \mathrm{~W}$ is supplied to the heater.

A temperature of $210^{\circ} \mathrm{C}$ was not chosen in arbitrarily fashion. It was arrived through experiments using various working fluids like Nitrogen, Methane and their mixture with Ethane, Propane and Iso-butane. The discharge pressure was restricted to 18 bar. A heater surface temperature of $210^{\circ} \mathrm{C}$ was observed. Based on these criteria a heater surface temperature of $210^{\circ} \mathrm{C}$, so as to restrict the highest pressure to 18 bar during the discharge conditions. The same was continued for all other experiments also as the highest heater surface temperature. The variation of temperature during heating and desorption process is shown in figure 4 . The system could not be heated till a steady state condition is obtained as the cycle time for such a refrigerator is about $30 \mathrm{~min}$.

\section{Experimental set-up}

A complete refrigerator working on Linde-Hampson cycle [2] consists of adsorption/desorption chamber, after cooler, return gas recuperative heat exchanger, capillary tube as the throttling device, a box-shaped evaporator. The components are connected using SS 304 tubing. The return gas heat exchanger, capillary tube and evaporator are enclosed in a vacuum chamber to prevent heat entering from the surroundings. Based on the experimental results obtained using a single and two cell set-up $[9,10]$ a proto-type fourcell sorption compressor based J-T refrigerator developed is as shown in figures 5(a) and (b). The complete assembly of a sorption compressor based J-T refrigerator is shown in figures 5(a) and (b) shows the recuperative tube in tube heat exchanger. The adsorber chamber is fabricated from schedule 10 stainless steel (SS) 316 seamless pipe of $80 \mathrm{~mm}$ diameter. This tube is enclosed by a $100 \mathrm{~mm} \mathrm{SS}$ 304 schedule 10 pipe. Detailed description is given in reference [10].

The gas is distributed inside the adsorber chamber with the help of a manifold. The manifold consists of a centrally placed capillary tube, surrounded by four other such tubes, running along the length of the chamber at right angle to each other. Each capillary tube is of $2 \mathrm{~mm}$ diameter. The gas passages are created by providing small openings along the lengths of the capillary tubes at a regular interval of $80 \mathrm{~mm}$. This ensures a uniform gas distribution in the adsorber chamber. 

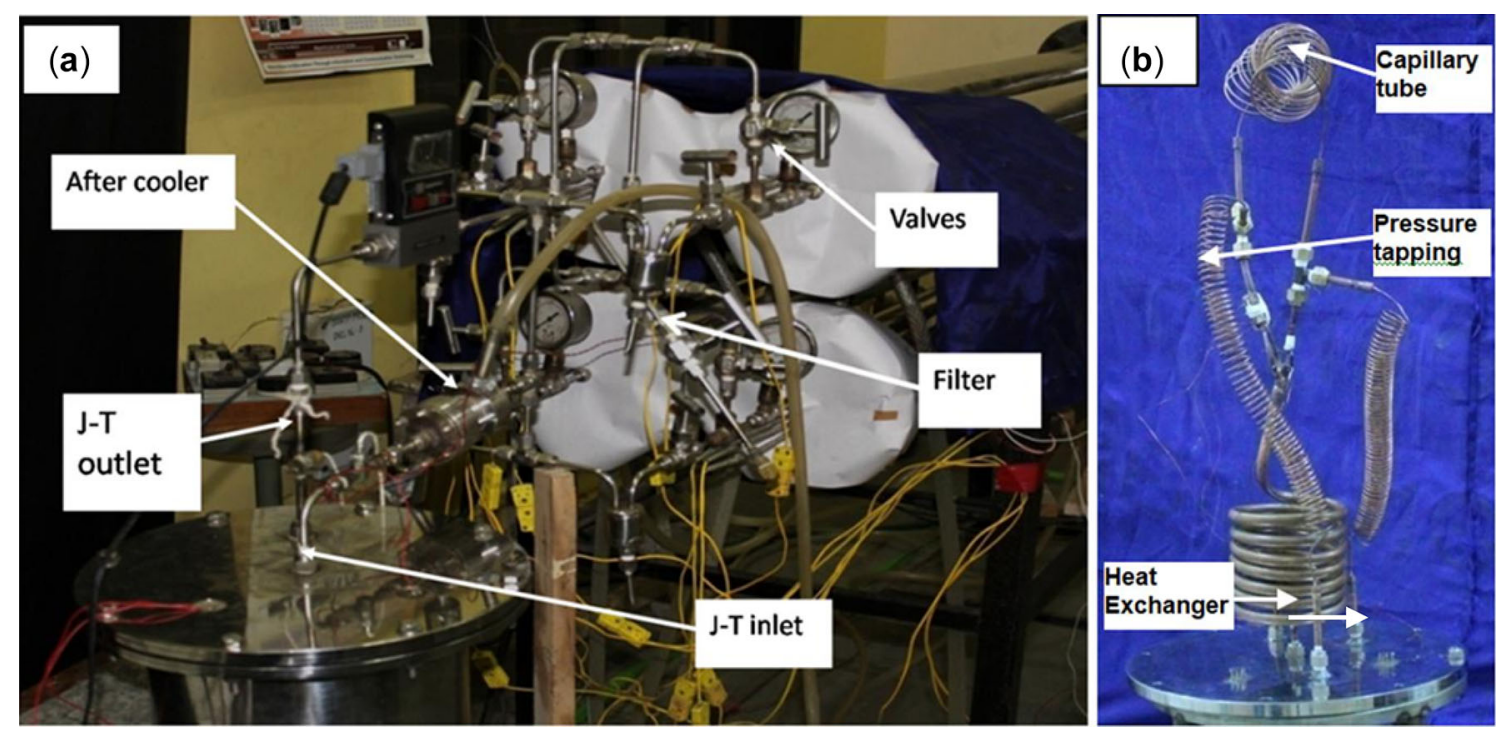

Figure 5. (a) Sorption compressor based refrigerator. (b) Return gas heat exchanger [10].

The annular space between the two pipes is used to circulate cooling water at $16^{\circ} \mathrm{C}$. The adsorber chamber of $2 \mathrm{~m}$ length is filled with activated carbon weighing 4330 grams. This results in a packing density/amount of adsorbent per unit volume as $433 \mathrm{~kg} / \mathrm{m}^{3}$. It also houses a gas distribution manifold comprising of five $2 \mathrm{~mm}$ outer diameter capillary tube to distribute the gas inside the adsorber cell and a heating system consisting of tubular heater arranged in a hexagonal fashion with fins at a regular interval of $80 \mathrm{~mm}$ to heat the carbon during desorption. Tubing made from SS 304 with $6.35 \mathrm{~mm}\left(1 / 4^{\prime \prime}\right)$ outer diameter and $4.5 \mathrm{~mm}$ inner diameter is used for connections. Manually operated needle valves are used at this stage to operate the cooler in cyclic operation. The system is supported for control and data acquisition by a LABview platform. Cooling water at $16^{\circ} \mathrm{C}$ is circulated through it to remove the heat supplied for desorption. The return gas heat exchanger is a tube in tube heat exchanger $[18,19]$. The outer tube is a $12 \mathrm{~mm}\left(1 / 2^{\prime \prime}\right)$ outer diameter refrigeration class tube and inner tube is a 6 $\mathrm{mm}$ copper tube. The length of the heat exchanger is $5.5 \mathrm{~m}$. A copper capillary tube is used for expansion of the gas from high pressure to low pressure. The evaporator is a rectangular box made up of copper sheet; Nichrome wire heater being mounted on this to simulate the heat load on the system. Helium gas is considered to be a gas with almost zero adsorption capacity.

Therefore, helium is used for measuring the void volume in the adsorber cell. Helium is charge in a buffer chamber with known volume at a specified pressure. It is then made to pass through the adsorber cell. From the change in pressure the void volume is calculated. The schematic of a four cell compressor refrigerator with instrumentation is shown in figure 6. The mass flow meter used is a sierra make smarttrek 50 series instrument.

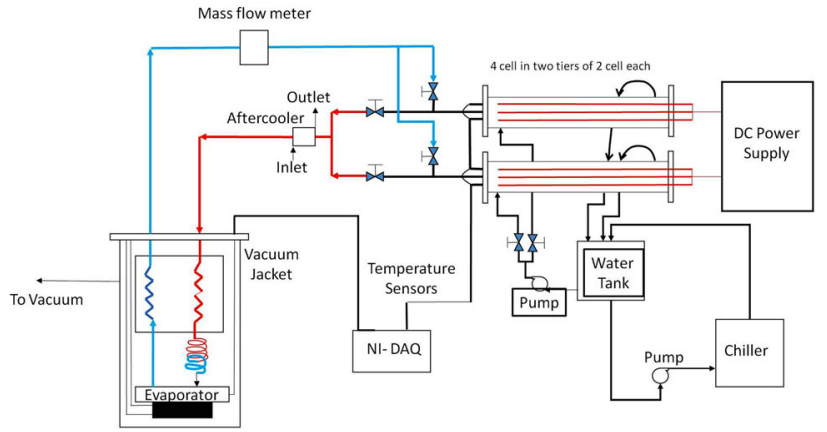

Figure 6. Schematic of sorption compressor based refrigerator with instrumentation.

\section{Results and discussions}

The test set-up was made ready, leak tested and evacuated. The initial experiments were conducted using R134a alone as the working fluid. The working fluid is charged to all the cells. To begin with, R134a alone as the working fluid is used and a heat input of $890 \mathrm{~W}$ is supplied for the desorption process to one of the four cells of the sorption compressor. The maximum discharge pressure and the adsorption pressure during the initial $1600 \mathrm{~s}$ of operation are found to be 10 bar and 1.8 bar, respectively. However, the refrigerator could not be operated continuously, as the mass flow rate seized to zero over a period of time. This phenomenon is observed because of the freezing of moisture from the refrigerant and the system in the capillary tube. After several trials, this problem is overcome by installing a commercially available Danfoss make sillicagel type dryer to remove the desorbed water vapour. This filter dryer is fitted at the outlet of the after cooler. 
The work is extended further to investigate long term operation using R134a as the working fluid. The adsorption capacity of R134a is determined using Eqs. (1) and (2) as $0.682 \mathrm{~g} / \mathrm{g}$ at a pressure of $3 \mathrm{bar}$. However, experimentally, it is found to be $0.57 \mathrm{~g} / \mathrm{g}$. at a pressure of $3 \mathrm{bar}$. The gas R134a is simultaneously charged to all the cells, hence, the quantity of gas in all cells is expected to be uniform. At first steady state operation is achieved with a heater power of $615 \mathrm{~W}$ and is then subsequently reduced to 540 and $510 \mathrm{~W}$. A cycle time of $25 \mathrm{~min}(1500 \mathrm{~s})$ is achieved with a power input of $540 \mathrm{~W}$ resulting in total heat input of $810 \mathrm{~kJ}$. The mass of the adsorbate left behind in the cell in adsorbed state after desorption process is completed, is analogues to the gas in clearance volume of a conventional mechanical compressor. This can be minimized by ensuring no void spaces inside the adsorber chamber. The variations of operating parameters viz., desorption/discharge pressure, adsorption/suction pressure and refrigeration temperature during the quasisteady state operation, which is achieved after a few cycles of operation is shown in figure 7. A capillary tube of $0.78 \mathrm{~mm}\left(0.031^{\prime \prime}\right)$ diameter and $3 \mathrm{~m}$ length is used for throttling. A steady state discharge pressure of 5.8 bar and a suction pressure of $2.9 \mathrm{bar}$ is achieved. The average refrigeration capacity achieved at about $-8^{\circ} \mathrm{C}$ temperature is of $5 \mathrm{~W}$. The refrigerator is operated successfully for over $16 \mathrm{~h}$ without any discontinuity or problems.

The work is then further extended to understand the effect of different parameters, namely, heater power input, capillary tube length, cycle time and also the effect of refrigeration load on mass flow rate. The evaporator and return gas heat exchanger are insulated from the heat gain from the surrounding by enclosing them in a vacuum jacket. A vacuum of the order of $10^{-4}$ mbar is maintained.

\subsection{Effect of input power}

The variation of refrigeration temperature for the heater power of $615 \mathrm{~W}$ and $540 \mathrm{~W}$ with the same capillary tube

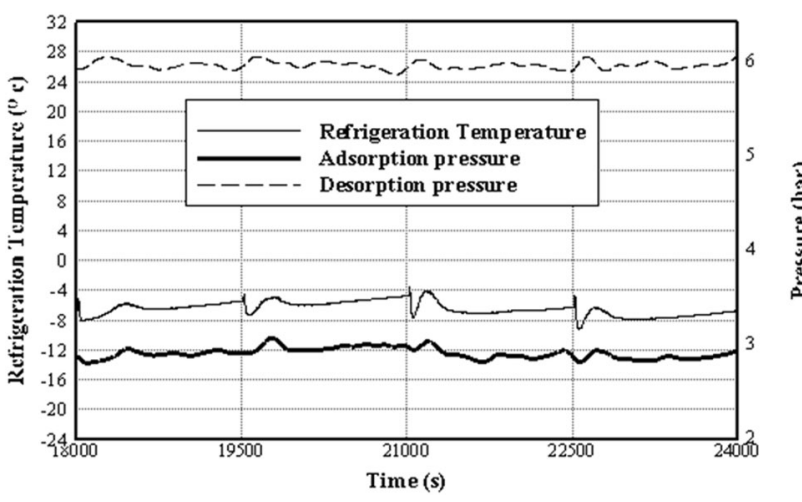

Figure 7. Variation of operating parameters during steady state operation in one cycle. length of $3 \mathrm{~m}$ and diameter $0.78 \mathrm{~mm}\left(0.031^{\prime \prime}\right)$ with the refrigeration load of $5 \mathrm{~W}$ is shown in figure 8 . The result for one complete cycle, consisting of four discharge processes of individual adsorber chamber is shown in the figure 8 . The variations of low temperature, for a higher $(615 \mathrm{~W})$ power input, is in the range of 7 to $-9^{\circ} \mathrm{C}$ while it is from -1 to $-9^{\circ} \mathrm{C}$ in the case of lower $(540 \mathrm{~W})$ heater power input. The mass flow rate for $615 \mathrm{~W}$ is found to vary from $0.85 \mathrm{~g} / \mathrm{s}$ to $0.25 \mathrm{~g} / \mathrm{s}$ for a discharge period of $1500 \mathrm{~s}$ for each cell, whereas, in the case of $540 \mathrm{~W}$ power input, the mass flow varies from $0.4 \mathrm{~g} / \mathrm{s}$ to $0.16 \mathrm{~g} / \mathrm{s}$ for a similar discharge pressure. The power required for cooling the chilled water is calculated as $1.0 \mathrm{~kW}$. In both the cases, the mass flow rate during the initial $150 \mathrm{~s}$ rises from minimum (end of the previous discharge) to maximum for the current discharge, it then decreases gradually to the minimum. A similar trend in the fluctuation of low temperature is observed. The low temperature significantly rises during this initial $150 \mathrm{~s}$ of operation and then decreases. This variation in the low temperature may be attributed to the limiting value of adsorption in the cell during the adsorption process and also due to inefficient heat transfer in the heat exchanger due to high mass flow rate.

The heater power input and the mass of the gas charged have a significant effect on the performance of the system. For a given packing density or void volume arising out of inter particle space and macro pore of the adsorbent, with the same amount of gas charged in the system, the high pressure generated and the mass flow rate delivered by a sorption compressor, primarily depend on the rate of heat supplied. However, this dependency is not linear. At lower heat input, desorption is extremely poor and the compressor fails to generate desired high pressure and also the mass flow rate. If the heat input is increased, the rate of desorption increases substantially due to non-linear relationship between the two. Therefore, for the same higher pressure generated, the mass flow rate generated at higher power is appreciably higher during the initial period of

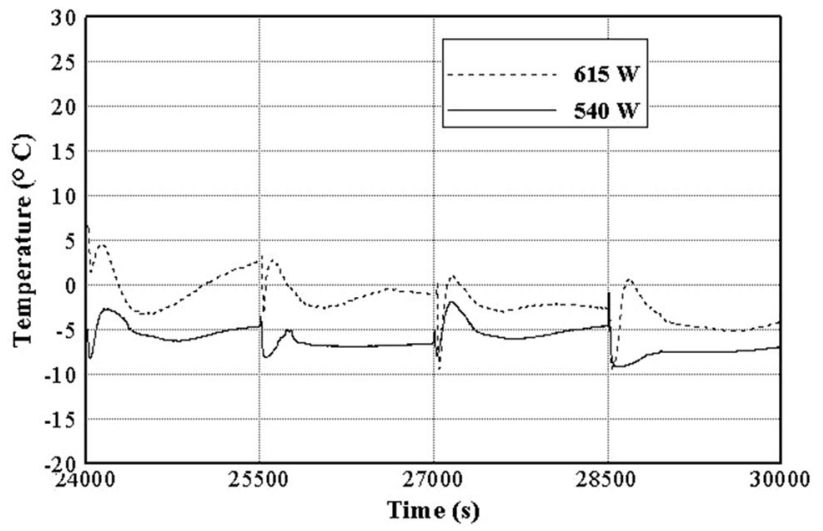

Figure 8. Effect of input power on refrigeration temperature. 
operation. The variation in low temperature can be reduced by increasing the corresponding rate of adsorption, e.g., by cooling the adsorber cell. This explains the rise of low temperature for higher wattage on account of variations in mass flow rate. Further, no desorption is observed for heater power below $510 \mathrm{~W}$ even for a cycle time of $2100 \mathrm{~s}$ and hence no experiments are conducted below this heater wattage.

\subsection{Effect of capillary length}

Experiments are carried out using capillary tube of size $0.78 \mathrm{~mm}\left(0.031^{\prime \prime}\right)$ diameter with a length of $3 \mathrm{~m}$ and $4 \mathrm{~m}$. A cycle time of $1500 \mathrm{~s}$ and a heater power input of $540 \mathrm{~W}$ is kept constant in both the cases. In the case of a $3 \mathrm{~m}$ long capillary tube, a high pressure of 6.2 bar is generated against 5.9 bar for a $4 \mathrm{~m}$ long capillary tube. Similarly, adsorption pressures of 3 bar and 2.8 bar are observed for the $3 \mathrm{~m}$ and $4 \mathrm{~m}$ long capillary tube, respectively. The low temperature variation obtained for both the cases with respect to time under a quasi-steady state operation is shown in figure 9. It may be seen from the figure that, the temperature variation in the case of $3 \mathrm{~m}$ capillary tubes is of the order of $6^{\circ} \mathrm{C}$, while it is only $2-3^{\circ} \mathrm{C}$ in the case of a $4 \mathrm{~m}$ long capillary tube. This is due to higher mass flow rate variations in the case of $3 \mathrm{~m}$ long capillary tube as explained earlier. The mass flow rate during initial phase of each discharge is found to be higher and then it gradually decreases as the cycle progresses. This variation in mass flow rate for a longer capillary is less pronounced due to increased pressure drop across the capillary tube length. Therefore, variations in low temperature can be reduced by using a longer capillary tube.

\subsection{Effect of cycle time}

The variation of refrigeration temperature with respect to cycle time for a capillary tube of $0.78 \mathrm{~mm}\left(0.031^{\prime \prime}\right)$ diameter and $4 \mathrm{~m}$ length is studied for the fixed discharge pressure of 6 bar. The power required for a $1500 \mathrm{~s}$ cycle is $540 \mathrm{~W}$ as against $510 \mathrm{~W}$ for a $1800 \mathrm{~s}$ cycle. The variation in low temperature attained is shown in figure 10. The low temperature attained in the case of a $1800 \mathrm{~s}$ cycle is of the order of $-13^{\circ} \mathrm{C}$ with a variation of $9^{\circ} \mathrm{C}$. On the other hand, it is found to be $-8^{\circ} \mathrm{C}$ with a variation of only $3^{\circ} \mathrm{C}$ for a $1500 \mathrm{~s}$ cycle. This is due to the fact that a longer cycle time facilities for a better adsorber chamber cooling, leading to better adsorption and therefore lower temperature is achieved. The variation of mass flow rate in the case of a $1500 \mathrm{~s}$ cycle is less as compared to those for $1800 \mathrm{~s}$ cycle. This is attributed to the non-linear desorption of the gas. On further experiment, it is found that lowest variations in temperature are found for $540 \mathrm{~W}$ with a cycle time of $1500 \mathrm{~s}$.

\subsection{Effect of refrigeration load on refrigerant mass flow rate}

Experiments are carried out at $0 \mathrm{~W}, 2.5 \mathrm{~W}$ and $5 \mathrm{~W}$ refrigeration loads at the operating conditions of heater wattage of $510 \mathrm{~W}$, capillary tube of length $4 \mathrm{~m}$ and cycle time $1800 \mathrm{~s}$. Figure 11 shows the variation of mass flow rate with cycle time for various refrigeration loads. No significant variation in the low temperature is observed with different heat loads. However, a significant effect on mass flow rate is observed. The variations of mass flow rate in the case of no load and $2.5 \mathrm{~W}$ heat load is observed from figure 11 as $0.15-0.74 \mathrm{~g} / \mathrm{s}$ and $0.12-0.74 \mathrm{~g} / \mathrm{s}$, respectively. However, it reduces to $0.45-0.15 \mathrm{~g} / \mathrm{s}$ in case of $5 \mathrm{~W}$ heat load. This can be attributed to higher volume of gas due to the evaporation on account of higher heat load. In the case of a sorption compressor, the driving force for circulation of refrigerant is the pressure difference between the evaporator outlet and the adsorber chamber pressure. This driving force remains the same for a particular temperature of cooling water/adsorption temperature. The mass flow

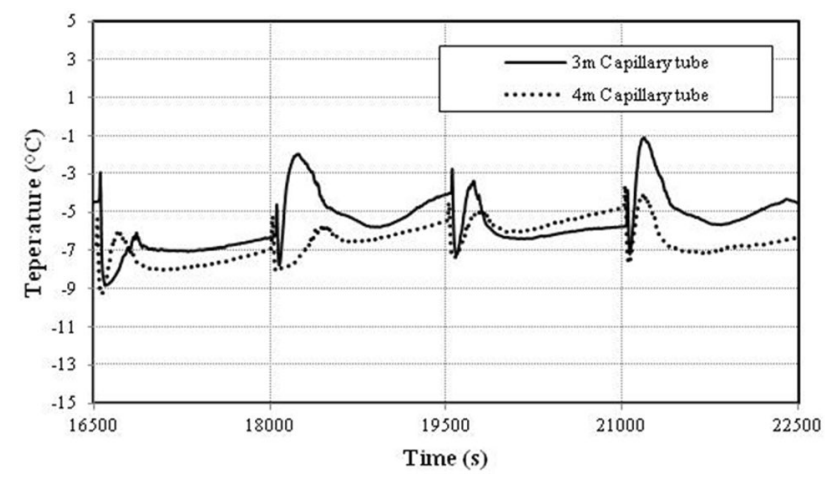

Figure 9. Effect of capillary tube length on refrigeration temperature.

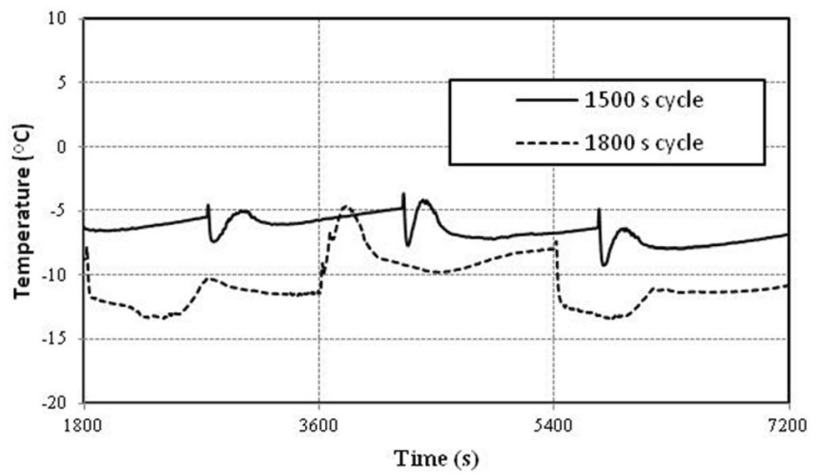

Figure 10. Effect of cycle time on refrigeration temperature. 


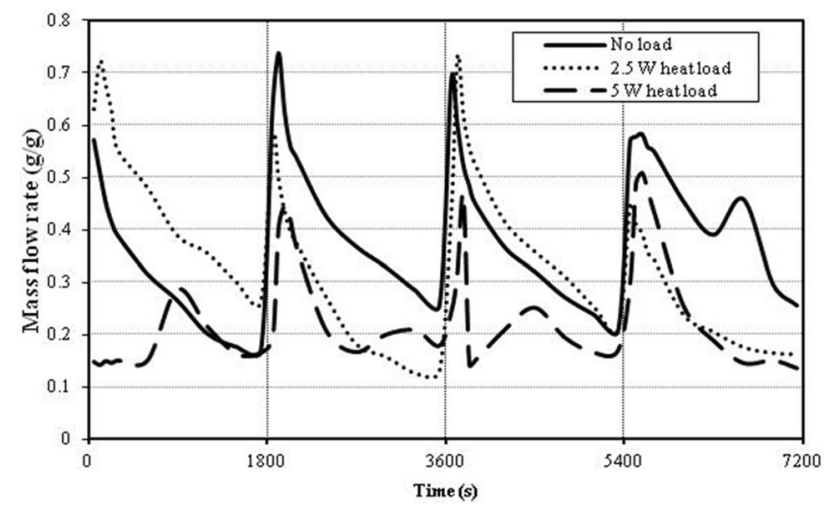

Figure 11. Effect of heat load on mass flow rate.

rate decreases with the increase in heat load due to increased quantity of vapor. This results in increased pressure at the entrance to the adsorber cell, thereby reducing the differential pressure across the evaporator inlet and compressor inlet.

The reduction in the differential pressure reduces the maximum mass flow rate from 0.7 to 0.45 from no load to $5 \mathrm{~W}$ heat load.

\subsection{Experiments using a three component mixture of R134a, Ethane and Methane}

The sorption compressor based cooler is developed and complete diagnostics for such a cooler are developed using R134a alone as the working fluid. Experiments are then conducted using a mixture of R134a, Ethane and Methane in the same set-up. The mixture components are chosen based on boiling point, temperature-enthalpy diagram and adsorption capacities for individual components. This is usually used in the case of Mixed Refrigerant J-T coolers using mechanical compressors [18, 19]. The low temperature achieved improved with mixture as the working fluid. The lowest temperature recorded is $-54^{\circ} \mathrm{C}$ under no load condition with a concentration of $47.6 \%, 43.3 \%$ and $9.1 \%$, of R134a, Ethane and Methane, respectively. A capillary tube of diameter $0.8 \mathrm{~mm}\left(0.031^{\prime \prime}\right)$ and length $4 \mathrm{~m}$ is used as the throttling device. Heater power of $1060 \mathrm{~W}$ is supplied for a cycle time of $35 \mathrm{~min}$. The maximum deviation in low temperature is found to be $+12^{\circ} \mathrm{C}$ with desorption pressure variations from 11 bar to 6 bar. The adsorption pressure remains steady at 1.6 bar. The variations in low temperature, desorption pressure and the adsorption pressure for one complete cycle is shown in figure 12. The deviation in the desorption pressure and the refrigeration temperature is on account of the poor adsorption capacities of Ethane and Methane as compared to R134a.

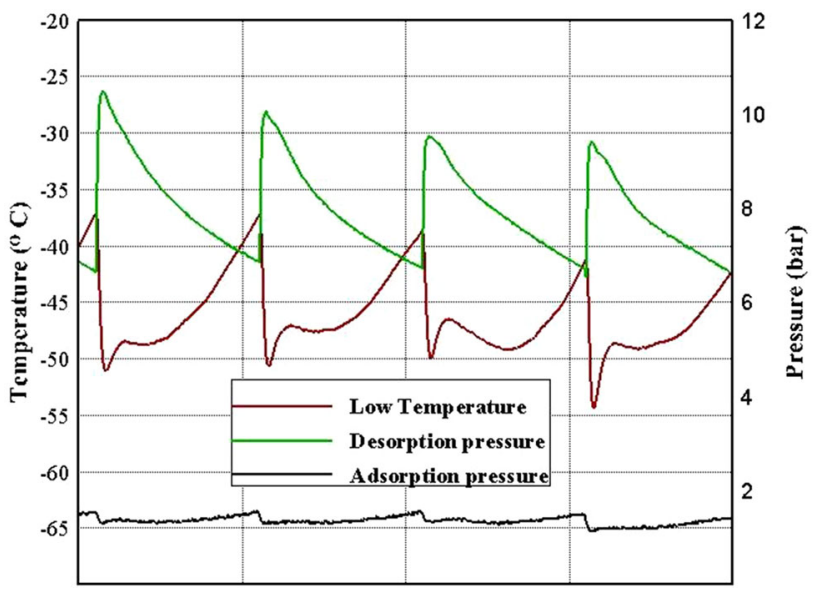

Figure 12. Lowest refrigeration temperature achieved using three component mixture.

\section{Conclusions}

A sorption compressor based cooler consisting of Compressor, after cooler, return gas heat exchanger is designed and developed in the current work. The theoretical adsorption capacity for R134a, Ethane and Methane is determined and is also experimentally verified. Experimental investigations are performed using R134a alone and a three component mixture of R134a, Ethane and Methane as the working fluid. The experiments are carried out for a long continuous duration and a refrigeration temperature in the range of $-8^{\circ} \mathrm{C}$ with a refrigeration load of $5 \mathrm{~W}$ is obtained using R134a alone as the working fluid. The study further highlights variation of refrigerant flow rate and its effect on temperature for different operating conditions like input power, capillary tube, cycle time and refrigeration load, etc. The experiments conducted using R134a single working fluid show that, an extended cycle time can result in lower temperature but with higher temperature variations. The work is further is further extended to obtain lower temperature using three component mixture of R134a, Ethane and Methane. A low temperature of $-54^{\circ} \mathrm{C}$ is attained using such a mixture as the working fluid.

\section{Nomenclature}

$\mathrm{E}_{\mathrm{O}} \quad$ characteristic energy of the surface, $\mathrm{kJ}$;

$\mathrm{p}$ pressure, $\mathrm{N} / \mathrm{m}^{2}$;

$\mathrm{p}_{\mathrm{s}} \quad$ saturation pressure, $\mathrm{N} / \mathrm{m}^{2}$;

$\mathrm{R} \quad$ gas constant, $\mathrm{J} / \mathrm{mol} \mathrm{K}$;

W equilibrium adsorption capacity of adsorbent, $\mathrm{g} / \mathrm{g}$;

$\mathrm{W}_{\mathrm{O}}$ micropore volume of adsorbent, $\mathrm{m}^{3} / \mathrm{g}$;

$\beta_{\mathrm{a}} \quad$ shifting factor;

$\rho \quad$ density of the working gas, $\mathrm{m}^{3} / \mathrm{kg}$; 


\section{References}

[1] Duband L and Coolaudin B 1999 Sorption coolers development at CEA - SBT. Cryogenics 39: 659-663

[2] Haselden G G 1971 Cryogenic Fundamentals. California: Academic Press chapter, 375p

[3] Parry Robert H and Green Don W 2007 Parry's Chemical Engineer's Hand book. New York: Mc Graw-hill Professional, chapter 16

[4] Rane M V, Kota Reddy S V, Agarwal A and Bajaj J S 2003 Energy efficient sorption processes and systems. Pub. No.: US 2003/0221438 A1

[5] Boubakri A 2006 Performance of an adsorptive solar ice maker operating with a single double function heat exchanger (evaporator/condenser). Renewable Energy 31: 1799-1812

[6] Chan C K 1999 Dynamic design of Gas Sorption J-T Refrigerator. Advances in Cryogenics 37: 819-827

[7] Huinik S A J, Burger J F, Holland H J, Van der sar E G, Gardener J G E, Ter Brake H J M and Rogalla H 1997 Experiments on charcoal/nitrogen sorption compressor and model considerations. Cryocooler 9: 569-579

[8] Prasad M, Akkimardi S, Rastogi S C, Rao R and Srinivasan K 1996 Adsorption characteristics of the charcoal-nitrogen system at $79-320 \mathrm{k}$ and pressures to $5 \mathrm{M}$ pa. Carbon 34 : 1401-1406

[9] Mehta R N, Bapat S L and Atrey M D 2012 Characterization of Sorption Compressor for Mixed Refrigerant J-T cryocooler. American Institute of Physics, Melville, NY. Advances in Cryogenics 57: 1797-1804

[10] Mehta R N, Bapat S L and Atrey M D 2014 Design and Development of a Four-Cell Sorption Compressor Based J-T cooler using R134a as Working Fluid. Advances in Cryogenics 59B: 1055-1062

[11] Zeng T, Huang Y, Kobayashi N and Li J 2017 Performance of an Activated Carbon-Ammonia Adsorption Refrigeration System. Natural Resources 8: 611-631

[12] Wiegerinck F M, Burger J F, Holland H J, Hondebrink E, Ter Brake H J M and Rogalla H A 2006 sorption compressor with a single sorber bed for use with a Linde-Hampson cold stage. Cryogenics 46: 9-20

[13] Wade L, Ryba E, Weston C and Alvarez J 1992 Test performance of a $2 \mathrm{~W}, 137 \mathrm{~K}$ sorption refrigerator. Cryogenics 32: $122-126$

[14] Hutson Nick D and Yang Ralph T 1997 Theoretical Basis for the Dubinin-Radushkevitch (D-R) Adsorption Isotherm Equation. Adsorption 3: 189-195

[15] Wood G O 2001 Affinity coefficients of the Polanyi /Dubinin adsorption isotherm Equations A review with compilations and correlations. Carbon 39: 343-356

[16] Chan C K, Tward E and Boudaia K I 1984 Adsorption isotherms and heats of adsorption of hydrogen, neon and nitrogen on activated charcoal. Cryogenics 34: 256-263

[17] Alvarez J F, Krylo R J, Snapp R D, Weston C, Sywulka P and Bell G C 1997 Development of an Advanced Sorption cooler and its application in a $125 \mathrm{~K}$. Cryocooler 9: 569-579

[18] Walimbe N S, Narayankhedkar K G and Atrey M D 2008 Experimental Investigation of Mixed Refrigerant Joule Thomson (MR JT) cryocooler. Advances in Cryogenic Engineering 53A: 11-16

[19] Ardhapurkar P M, Sridharan A and Atrey M D 2014 Flow boiling heat transfer coefficients at cryogenic temperatures for multi-component refrigerant mixtures of nitrogen-hydrocarbons. Cryogenics 59: 84-92 